\title{
TWO-HUNDRED YEARS LATER: IS PARKINSON'S DISEASE A SINGLE DEFINED ENTITY?
}

\author{
Mayela Rodríguez-Violante ${ }^{1 *}$, Amin Cervantes-Arriaga ${ }^{1}$, Stanley Fahn ${ }^{2}$ and Eduardo Tolosa ${ }^{3}$ \\ ${ }^{1}$ Movement Disorders Clinic, National Institute of Neurology and Neurosurgery, Mexico City, Mexico; ${ }^{2}$ Department \\ of Neurology, Columbia University Medical Center, New York, USA; ${ }^{3}$ Neurological Tissue Bank, Hospital Clinic-Institut \\ d'Investigacions Biomèdiques August Pi i Sunyer (IDIBAPS), Barcelona and Centro de Investigación Biomédica en Red sobre
} Enfermedades Neurodegenerativas, Madrid and Universidad de Barcelona, Barcelona, Spain

\begin{abstract}
An Essay on the Shaking Palsy, by James Parkinson, was published in 1817. Later, Jean-Martin Charcot better described some of the motor features of the disease and named the condition as "La Maladie de Parkinson." As understanding about the disease progressed, aided by both clinical expertise and technological developments, the definition of what is Parkinson's disease has evolved. Motor phenotype, non-motor symptoms, monogenic mutations, genetic risk factors, disease subtyping, and data-driven clusters, among other concepts, have given rise to the hypothesis that Parkinson's disease may be not one well-defined entity but several different diseases encompassed as a levodopa-responsive Parkinsonism. This review present and discusses several of these factors and how they may support or not the notion of Parkinson's being one or more diseases. In summary, current evidence appears to be insufficient at this moment to clarify this issue. Parkinson's disease will continue to be an evolving concept over the years to come.
\end{abstract}

Key words: Parkinson's disease. Definition. Subtypes.

\section{INTRODUCTION}

Parkinson's disease (PD) was described 200 years ago but as knowledge on the disease has increased, the question of whether it is a single entity or, on the contrary, a group of distinct diseases has arisen. While the condition easily fulfills the common definition of "disease," certain issues may suggest that PD could have different causes, thus encompassing more a syndrome and consequently representing not one but many diseases.

\section{Corresponding author:}

*Mayela Rodríguez-Violante

Movement Disorders Clinic

National Institute of Neurology and Neurosurgery

Insurgentes Sur, no 877

Col. La Fama

C.P. 14269, Ciudad de México, Mexico

E-mail: mrodriguez@innn.edu.mx
Following the original description of PD by James Parkinson, the disease became a fairly well-defined clinical entity. Nevertheless, advances through the years in several fields such as pathology, molecular biology, and neuroimaging, and the reappraisal of the importance of non-motor symptoms have led to questioning the definition for the disease. In 1912, Fritz Heinrich Lewy identified the inclusion bodies that are still considered the pathological hallmark of $\mathrm{PD}^{1}$, and Konstantin Tretiakoff the loss of neurons in the substantia nigra (SN) in 1919 while Kathleen Montagu and

Received for publication: 17-05-2017

Approved for publication: 14-06-2017

doi: $10.24875 /$ RIC.17002291 
Table 1. Historical landmarks in Parkinson's disease and changes in definition over time

\begin{tabular}{|c|c|c|c|c|c|}
\hline 1817 & 1861 & 1912 & 1919 & 1957 & 1960 \\
\hline James & Jean-Martin & Frederick Henry & Konstantin & Kathleen Monatgu & Oleh \\
\hline $\begin{array}{l}\text { Parkinson } \\
\text { describes } \\
\text { six patients } \\
\text { with paralysis } \\
\text { agitans }\end{array}$ & $\begin{array}{l}\text { Charcot betters } \\
\text { characterize } \\
\text { the clinical } \\
\text { phenomenology. } \\
\text { Suggests the use } \\
\text { of the thermal } \\
\text { "PD" }\end{array}$ & $\begin{array}{l}\text { Lewy reports } \\
\text { the presence of } \\
\text { intraneuronal } \\
\text { inclusions in } \\
\text { the brain of } \\
\text { patient's with } \\
\text { PD }\end{array}$ & $\begin{array}{l}\text { Tretiakoff } \\
\text { reports that } \\
\text { the } \mathrm{SN} \text { is the } \\
\text { main structure } \\
\text { affected }\end{array}$ & $\begin{array}{l}\text { and Arvid Carlsson } \\
\text { separately } \\
\text { reported } \\
\text { dopamine as a } \\
\text { neurotransmitter }\end{array}$ & $\begin{array}{l}\text { Hornykiewicz } \\
\text { report that } \\
\text { dopamine } \\
\text { concentrations } \\
\text { are diminished }\end{array}$ \\
\hline $\begin{array}{l}\text { A neurological } \\
\text { condition with } \\
\text { involuntary } \\
\text { tremor, } \\
\text { muscular } \\
\text { weakness and } \\
\text { propensity to } \\
\text { bend forward }\end{array}$ & $\begin{array}{l}\text { PD is a } \\
\text { neurological } \\
\text { condition with } \\
\text { tremor, rigidity } \\
\text { and slowness of } \\
\text { movements } \\
\text { (parkinsonism) }\end{array}$ & $\begin{array}{l}\text { PD is a } \\
\text { neurological } \\
\text { condition with } \\
\text { parkinsonism } \\
\text { and the } \\
\text { presence of } \\
\text { Lewy Bodies }\end{array}$ & $\begin{array}{l}\text { PD is a } \\
\text { neurological } \\
\text { condition with } \\
\text { parkinsonism, } \\
\text { presence of } \\
\text { Lewy Bodies, } \\
\text { and neuron } \\
\text { loss in the SN }\end{array}$ & $\begin{array}{l}\text { PD is a } \\
\text { neurological } \\
\text { condition with } \\
\text { parkinsonism, } \\
\text { presence of Lewy } \\
\text { Bodies, neuron } \\
\text { loss in the SN, and } \\
\text { deficit of brain } \\
\text { dopamine }\end{array}$ & \\
\hline 1967 & 1988 & 1997 & 2011 & 2015 & \\
\hline $\begin{array}{l}\text { George } \\
\text { Cotzias } \\
\text { showed motor } \\
\text { improvement } \\
\text { after oral } \\
\text { L-dopa } \\
\text { administration }\end{array}$ & $\begin{array}{l}\text { Andrew J. Lees } \\
\text { and WR Gibb } \\
\text { publish the UK } \\
\text { Parkinson's } \\
\text { Disease Society } \\
\text { Brain clinical } \\
\text { diagnostic criteria }\end{array}$ & $\begin{array}{l}\text { First genetic } \\
\text { cause of PD is } \\
\text { identified } \\
\text { (SNCA) }\end{array}$ & $\begin{array}{l}\text { New risk factor } \\
\text { mutations are } \\
\text { reported using } \\
\text { genome-wide } \\
\text { association } \\
\text { studies }\end{array}$ & $\begin{array}{l}\text { Movement } \\
\text { disorder society } \\
\text { clinical diagnostic } \\
\text { criteria are } \\
\text { published }\end{array}$ & \\
\hline $\begin{array}{l}\text { PD is a } \\
\text { neurological } \\
\text { condition with } \\
\text { parkinsonism } \\
\text { responsive } \\
\text { to L-dopa, } \\
\text { presence of } \\
\text { Lewy Bodies, } \\
\text { neuron loss } \\
\text { in the SN, } \\
\text { deficit of brain } \\
\text { dopamine }\end{array}$ & $\begin{array}{l}\text { PD is a } \\
\text { neurological } \\
\text { condition with } \\
\text { parkinsonism } \\
\text { defined as } \\
\text { bradykinesia plus } \\
\text { tremor and/or } \\
\text { rigidity and/or } \\
\text { postural instability, } \\
\text { responsive to } \\
\text { L-dopa, and with } \\
\text { an asymmetrical } \\
\text { onset }\end{array}$ & $\begin{array}{l}\text { PD is a } \\
\text { neurological } \\
\text { condition } \\
\text { with L-dopa } \\
\text { responsive } \\
\text { parkinsonism, } \\
\text { presence of } \\
\text { Lewy Bodies, } \\
\text { neuron loss } \\
\text { in the SN, } \\
\text { deficit of brain } \\
\text { dopamine, } \\
\text { and in some } \\
\text { cases with a } \\
\text { monogenetic } \\
\text { cause }\end{array}$ & $\begin{array}{l}\text { PD is a } \\
\text { neurological } \\
\text { condition } \\
\text { with L-dopa } \\
\text { responsive } \\
\text { parkinsonism, } \\
\text { presence of } \\
\text { Lewy Bodies, } \\
\text { neuron loss } \\
\text { in the SN, } \\
\text { deficit of brain } \\
\text { dopamine and } \\
\text { genetic risk } \\
\text { factors }\end{array}$ & $\begin{array}{l}\text { PD is a } \\
\text { multisystemic } \\
\text { condition with } \\
\text { parkinsonism, } \\
\text { responsive to } \\
\text { dopaminergic } \\
\text { treatment } \\
\text { presence of } \\
\text { Lewy Bodies, } \\
\text { neuron loss in } \\
\text { the SN, deficit of } \\
\text { neurotransmitters } \\
\text { and genetic risk } \\
\text { factors }\end{array}$ & \\
\hline
\end{tabular}

PD: Parkinson's disease, SN: Substantia nigra, SNCA: $\alpha$-synuclein encoded by the PARK1/4 gene

Arvid Carlsson described the presence of dopamine in the brain and its relevance in the striatum ${ }^{2,3}$. Additional important milestones followed: Polymeropoulos et al. discovered in 1997 a mutation in the alpha-synuclein ( $\alpha$-syn) gene (SNCA) in a family with autosomal dominant $\mathrm{PD}^{4}$ and immediately $\alpha$-syn was identified as the main constituent of the Lewy inclusions ${ }^{5}$.

Whether PD is one or many diseases remains a difficult question to answer. The objective of this review has been to highlight recently gained knowledge of the disorder and discuss how it applies to this important question.

\section{HOW IS A DISEASE DEFINED?}

Defining a disease can be elusive and controversial. The Oxford English Dictionary defines disease as "a disorder of structure or function in a human, animal, or plant, especially one that produces particular symptoms or that affects a specific location and is not simply a direct result of physical injury." PD applies to this definition since it is associated to a disordered structure and function of the basal ganglia and comprises typical symptoms hallmarked by Parkinsonism. 
Another commonly used definition of disease is the one established by the World Health Organization which states that a disease is an "alteration or deviation of the physiological state in one or more parts of the body, by generally known causes, manifested by more or less characteristic signs and symptoms and whose evolution is more or less predictable." All these statements apply to our current definition of PD. In summary, PD fulfills the above criteria to be considered a disease.

\section{PD: AN EVOLVING CONCEPT}

Our concept of PD has evolved through the years (Table 1). James Parkinson hallmarked the disease by two major motor symptoms: An involuntary tremulous motion, and a propensity to bend forward and pass from a walking to a running pace. Later, the concept of PD as a syndrome characterized by movement disorders consisting of tremor, rigidity, bradykinesia, and postural abnormalities, associated with a distinctive pathology (Lewy type inclusions) was highlighted 6 . A more recent definition of PD comprises the classical motor features, Lewy type inclusions and other protein aggregates involving extensive regions throughout the brain, abnormalities of several neurotransmitters, and clinically significant non-motor symptoms ${ }^{7}$. In 2014, the International Parkinson and Movement Disorders Society (MDS) commissioned a task force to redefine PD according to the most recent knowledge. The MDS definition of PD includes: (1) A motor clinical syndrome, with levodopa-responsive Parkinsonism, typical clinical characteristics, and an absence of markers suggestive of another disease. (2) Pathologic confirmation of $\alpha$-synuclein deposition and dopamine neuronal loss in the SN pars compacta. This definition is merely a clinicopathological one. Interestingly, the task force suggested the development of a "clinicogenetic" category and a redo of the current genetic PARK classification ${ }^{8}$. PD definitive diagnosis is still by pathology; at least until more reliable biomarkers of $\alpha$-synuclein deposits are available. At present, the clinical definition of a person with PD does not consider the possibility of separate diseases.

\section{SUBTYPES: PD VARIANTS OR DIFFERENT DISEASES?}

Two main procedures are frequently used to classify PD into subtypes: The hypothesis-driven method and the data-driven method. The hypothesis-driven method is based on clinical observation, whereas the data-driven method relies on statistical data analysis with no a priori hypothesis, e.g., cluster analysis ${ }^{9}$. Several comprehensive reviews on cluster analysis and its validation in PD has been published elsewhere ${ }^{10-12}$.

The most common subtype classification of PD is based on the motor phenotype. Three main groups have been identified: Postural instability and gait disturbance (PIGD) PD, tremor-dominant (TD) PD, and mixed PD (sometimes referred as indeterminate). PIGD cases respond less well to levodopa with fewer fluctuations and dyskinesia and are more prone to dementia in comparison to TD patients ${ }^{13-16}$.

Age of onset appears to be somehow related with these motor phenotypes. Late-onset PD is associated with PIGD, whereas young-onset PD has been linked more frequently with a TD PD ${ }^{17}$. Studies using diffusion tensor imaging have reported that PIGD cases have a more severe microstructural change within the $\mathrm{SN}$ in comparison to those with a TD disease ${ }^{18}$. Furthermore, PIGD-specific hypoconnectivity within the striatum and in motor and cognitive control circuits has been reported. These findings support the association between PIGD subtypes and cognitive impairment ${ }^{19}$. Prospective studies on the prognostic value of motor subtypes are scarce. Rajput et al. conducted a longitudinal study on 166 patients with eventual autopsy-confirmed PD. Patients were classified into three subtypes: Akinetic/rigid, TD, and mixed subtypes. Age of onset was younger and progression slower in TD, whereas the worst course was reported for the akinetic/rigid subtype ${ }^{20}$.

In clinical practice, motor subtypes can be determined using the more recent revision of the unified Parkinson's disease rating scale (UPDRS) performed by the International Parkinson and Movement Disorder Society (MDS-UPDRS), where TD versus PIGD subtype is calculated as a ratio of the tremor ( 11 items) versus PIGD (5 items) mean scores ${ }^{21}$. An important issue is the fact that patients with PD may switch predominant motor subtype as the disease progresses. Simuni et al. investigated the stability over time of patients with PD initially categorized as TD, PIGD, or indeterminate. At 1-year follow-up, 39\% PIGD and 18\% TD shifted subtypes. The most frequent shift was from 
PIGD to TD ${ }^{22}$. A previous study in Norwegian patients also reported a high rate of shifts of motor subtype, but due to a longer follow-up for re-classification, the study suffered from high attrition ${ }^{23}$.

An extensive review and viewpoint on whether differences in etiology, pathology, imaging, and biomarkers can account for motor subtypes as biological distinct entities have been published recently ${ }^{24}$. In summary, motor phenotypes are currently useful for prognosis but still appear insufficient to separate them into different diseases.

Given the fact that virtually every patient with PD presents or will develop a non-motor symptom during the course of the disease, attempts have been made to subtype the disease based on such various symptoms and an empirical clinical-based classification has been suggested, which includes a predominantly cognitive subtype, apathy subtype, sleep disorder subtype, pain subtype, and autonomic subtype ${ }^{25}$. The usefulness of such a non-motor phenotyping remains to be established.

In clinical practice, patients with PD present with various combinations of motor and non-motor symptoms. Consequently, a mixed symptom profiling might be more useful. Unfortunately, the heterogeneity of clinical symptoms and phenotypes has limited this approach. Most studies to date have reported different clusters or subgroups depending on the study population, as well as on the methods and clinical tools used $^{26-31}$.

The existence of the various PD subtypes, as described above, may be an indication that we are dealing with different conditions or diseases and not one. Still, although the line between a disease subtype and a new disease is not clear, distinct phenotypes, genotypes or clusters are not necessarily equivalent to different diseases. The MDS has recently stated that: "Clinical subtypes should only be delineated if there are clear data that demonstrate consistent, large differences in prognosis, predicted disease manifestations, or treatment," and that "the search for subtypes should not be restricted to clinical features, but should include subtypes of molecular pathogenesis"s. The reasons for the profound clinical heterogeneity of PD have not been elucidated, and it remains to be determined whether the currently defined subtypes of PD represent different diseases. This evidence supporting such a view is minimal.

\section{IS GENETIC PD A DIFFERENT DISEASE?}

Historically, the possibility of PD being several diseases became apparent when mutated genes on different chromosomes causing a similar phenotype were identified.

The first finding suggesting the existence of a "genetic subtype" occurred with the identification of mutations in PARK2, and the unexpected absence of $\alpha$-synuclein deposits in autopsies of patients with this autosomal recessive juvenile form of $\mathrm{PD}^{32}$. Similarly, years later, it became apparent that in PD patients with mutations in leucine-rich repeat kinase 2 (LRRK2) gene $\alpha$-synuclein deposits could be absent ${ }^{33}$. These observations have favored the hypothesis that accumulation of $\alpha$-synloaded Lewy bodies is but a remnant of a defense mechanism against the dysfunction in the system of ubiquitination and intracellular proteolysis. This hypothesis is opposite to the common assumption of Lewy bodies being pathogenic.

Monogenic forms of PD, that is, PD resulting from modifications in a single gene, including both autosomal dominant (SNCA, LRRK2, EIF4G1, VPS35, and UCHL1) and autosomal recessive (parkin/PARK2, PINK1, and DJ1/PARK7). Several of these monogenic forms, including PARK2, PINK1, UCHL1, and DJ-1, are involved in the ubiquitin-proteasome system and/ or mitochondrial metabolism leading to cell death through similar pathways. Figure 1 shows a simplified representation of the overlapping pathways leading to neuronal death in different PARK genes.

The genetic overlap and convergent pathological mechanisms of SNCA, microtubule-associated protein tau (MAPT) and LRRK2 are of interest ${ }^{34}$. For example, regulation of the autophagy-lysosome system is dependent on microtubule transport in neurons, the latter being related to MAPT.

In summary, as mentioned before, some cases of genetic PD do not have the typical pathological finding associated with PD, despite having a known monogenic cause and a clear levodopa-responsive parkinsonian syndrome. This issue raises the possibility that 
Figure 1. Simplified representation of intracellular mechanisms disrupted by mutations in PARK genes leading to cell death. DJ1: Protein deglycase encoded by the PARK7 gene. LRRK2: Leucine-rich repeat kinase 2 (dardarin) encoded by the PARK8 gene. MAPT: Microtubule-associated protein tau. Parkin, ubiquitin protein ligase encoded by the PARK2 gene. PINK: PTEN induced putative kinase 1 encoded by the PARK6 gene. SNCA: $\alpha$-synuclein encoded by the PARK1/4 gene.

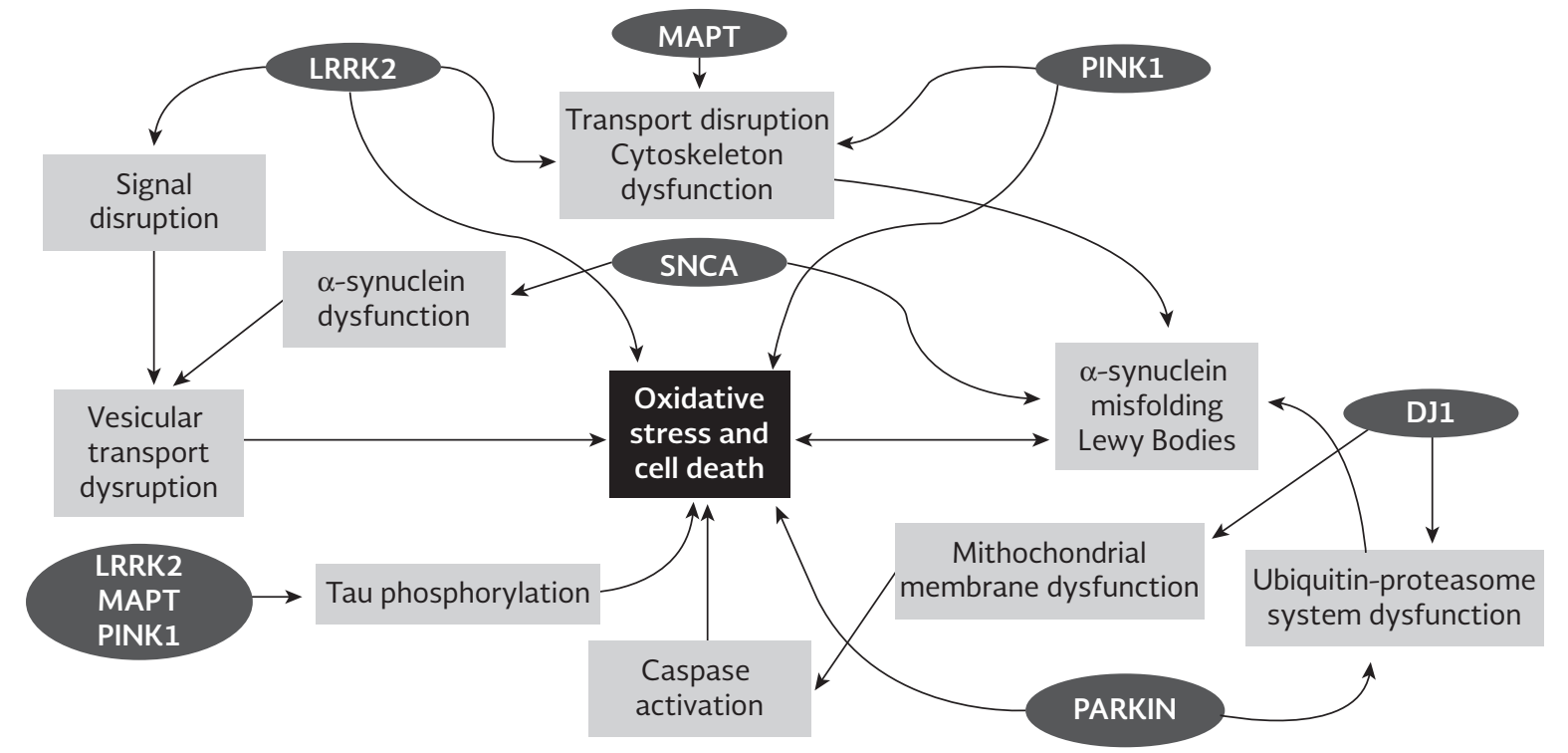

pathologically-defined PD and some genetically-defined PD might be different diseases. Nevertheless, both entities show a very similar clinical phenotype, and treatment does not differ. Conversely, known genes linked and/or associated with PD are involved in molecular pathways (synaptic transmission, endosomal trafficking, lysosomal autophagy, and mitochondrial metabolism) ${ }^{35}$. Mutations in one or more of these genes result in a similar phenotype hallmarked by Parkinsonism, and consequently, genetics alone may not suffice to break PD into different diseases. Still, genetics is of great importance to understand the physiopathology of PD and the development of future therapies.

\section{FINAL REMARKS}

The advances in the understanding of the etiology and pathological mechanisms of PD are insufficient to conclude whether PD is one disease with a broad spectrum of clinical, genetic and pathological findings, or represents several different diseases.

The most accepted definition of PD includes both a clinical syndrome with a characteristic pathological correlate. There are several problems to this approach: The clinical syndromes can be found in disorders with different types of pathological lesions, and $\alpha$-synuclein deposit is not exclusive of PD as it can also be found in multiple system atrophy, pure autonomic failure, or Alzheimer's disease. Advances in PD genetics, though, have shed light on the pathogenic mechanisms of PD and provided hard evidence that different causes (e.g., mutations in different genes) can result in a similar clinical and pathological condition.

Irrespective of what side we take on this "one disease versus many" issue, a pragmatic definition of PD is needed for daily clinical practice. Most clinicians would agree, and so do we, on the current gold standard definition of PD as a typical clinical syndrome - and absence of markers suggestive of other diseases- with neuronal loss in the substantia nigra, that responds to levodopa, and has distinctive Lewy type pathology that confirms the diagnosis, although PD is also seen without this pathologic hallmark, as mentioned above. Our understanding of PD is rapidly expanding, and new definitions will likely be soon forthcoming that incorporate no motor symptoms, but only a premotor diagnosis, as knowledge on the pathophysiology of neurodegeneration increases.

James Parkinson wrote on his An Essay on the Shaking Palsy: "The disease, respecting which the present inquiry is made, is of a nature highly afflictive. 
Notwithstanding which, it has not yet obtained a place in the classification of nosologists; some have regarded its characteristic symptoms as distinct and different diseases, and others have given its name to diseases differing essentially from it; while the unhappy sufferer has considered it as an evil, from the domination of which he had no prospect of escape." Now, 200 years after this statement was written, we are still lacking proper and irrefutable evidence on whether PD is a single or several diseases.

\section{REFERENCES}

1. Lewy FH. Paralysis agitans: Pathologische anatomie. Handbuch der Neurologie. Vol. 3. Berlin: Springer; 1912. p. 920-33.

2. Montagu KA. Catechol compounds in rat tissues and in brains of different animals. Nature. 1957;180:244-5.

3. Carlsson A, Lindqvist $M$, Magnusson T. 3, 4-Dihydroxyphenylalanine and 5-hydroxytryptophan as reserpine antagonists. Nature. 1957;180:1200.

4. Polymeropoulos MH, Lavedan C, Leroy E, et al. Mutation in the alpha-synuclein gene identified in families with Parkinson's disease. Science. 1997;276:2045-7.

5. Jakes R, Spillantini MG, Goedert M. Identification of two distinct synclines from human brain. FEBS Lett. 1994;345:27-32.

6. Marsden CD. Parkinson's disease. J Neurol Neurosurg Psychiatry. 1994;57:672-81

7. Kalia LV, Lang AE. Parkinson's disease. Lancet. 2015;386: 896-912.

8. Berg D, Postuma RB, Bloem B, et al. Time to redefine PD? Introductory statement of the MDS Task Force on the definition of Parkinson's disease. Mov Disord. 2014;29:454-62.

9. Kell DB, Oliver SG. Here is the evidence, now what is the hypothesis? The complementary roles of inductive and hypothesis-driven science in the post-genomic era. Bioessays. 2004; 26:99-105.

10. Marras C, Lang A. Parkinson's disease subtypes: Lost in translation? J Neurol Neurosurg Psychiatry. 2013;84:409-15.

11. Marras C. Subtypes of Parkinson's disease: State of the field and future directions. Curr Opin Neurol. 2015;28:382-6.

12. van Rooden SM, Heiser WJ, Kok JN, Verbaan D, van Hilten JJ, Marinus J. The identification of Parkinson's disease subtypes using cluster analysis: A systematic review. Mov Disord. 2010; 25:969-78.

13. Zetusky WJ, Jankovic J, Pirozzolo FJ. The heterogeneity of Parkinson's disease: Clinical and prognostic implications. Neurology. 1985;35:522-6.

14. Jankovic J, McDermott M, Carter J, et al. Variable expression of Parkinson's disease: A base-line analysis of the DATATOP cohort. The Parkinson study group. Neurology. 1990;40: 1529-34.

15. van der Heeden JF, Marinus J, Martinez-Martin P, RodriguezBlazquez C, Geraedts VJ, van Hilten JJ. Postural instability and gait are associated with severity and prognosis of Parkinson disease. Neurology. 2016;86:2243-50.
16. Burn DJ, Rowan EN, Allan LM, Molloy S, O'Brien JT, McKeith IG. Motor subtype and cognitive decline in Parkinson's disease, Parkinson's disease with dementia, and dementia with Lewy bodies. J Neurol Neurosurg Psychiatry. 2006;77:585-9.

17. Thenganatt MA, Jankovic J. Parkinson disease subtypes. JAMA Neurol. 2014;71:499-504

18. Nagae LM, Honce JM, Tanabe J, Shelton E, Sillau SH, Berman BD. Microstructural changes within the basal ganglia differ between Parkinson disease subtypes. Front Neuroanat. 2016;10:17.

19. Vervoort G, Alaerts K, Bengevoord A, et al. Functional connectivity alterations in the motor and fronto-parietal network relate to behavioral heterogeneity in Parkinson's disease. Parkinsonism Relat Disord. 2016;24:48-55.

20. Rajput $A H$, Voll A, Rajput ML, Robinson CA, Rajput A. Course in Parkinson disease subtypes: A 39-year clinic pathologic study. Neurology. 2009;73:206-12.

21. Stebbins GT, Goetz CG, Burn DJ, Jankovic J, Khoo TK, Tilley BC. How to identify tremor dominant and postural instability/gait difficulty groups with the movement disorder society-unified Parkinson's disease rating scale: Comparison with the unified Parkinson's disease rating scale. Mov Disord. 2013;28: 668-70.

22. Simuni T, Caspell-Garcia C, Coffey C, et al. How stable are Parkinson's disease subtypes in de novo patients: Analysis of the PPMI cohort? Parkinsonism Relat Disord. 2016;28:62-7.

23. Alves G, Larsen JP, Emre M, Wentzel-Larsen T, Aarsland D. Changes in motor subtype and risk for incident dementia in Parkinson's disease. Mov Disord. 2006;21:1123-30.

24. Nutt JG. Motor subtype in Parkinson's disease: Different disorders or different stages of disease? Mov Disord. 2016; 31:957-61.

25. Sauerbier A, Jenner P, Todorova A, Chaudhuri KR. Non motor subtypes and Parkinson's disease. Parkinsonism Relat Disord. 2016;22 Suppl 1:S41-6.

26. van Rooden SM, Visser M, Verbaan D, Marinus J, van Hilten J]. Patterns of motor and non-motor features in Parkinson's disease. J Neurol Neurosurg Psychiatry. 2009;80:846-50.

27. Erro R, Picillo M, Vitale $C$, et al. Clinical clusters and dopaminergic dysfunction in de-novo Parkinson disease. Parkinsonism Relat Disord. 2016;28:137-40.

28. van Rooden SM, Colas F, Martínez-Martín P, et al. Clinical subtypes of Parkinson's disease. Mov Disord. 2011;26:51-8.

29. Fereshtehnejad SM, Romenets SR, Anang JB, Latreille V, Gagnon JF, Postuma RB. New clinical subtypes of Parkinson disease and their longitudinal progression: A prospective cohort comparison with other phenotypes. JAMA Neurol. 2015;72:863-73.

30. Marras C, Chaudhuri KR. Nonmotor features of Parkinson's disease subtypes. Mov Disord. 2016;31:1095-2.

31. Lawton M, Baig F, Rolinski M, et al. Parkinson's disease subtypes in the oxford Parkinson disease centre (OPDC) discovery cohort. J Parkinsons Dis 2015;5:269-79.

32. Takahashi H, Ohama E, Suzuki S, et al. Familial juvenile parkinsonism: Clinical and pathologic study in a family. Neurology. 1994;44:437-1.

33. Zimprich A, Biskup S, Leitner $P$, et al. Mutations in LRRK2 cause autosomal-dominant parkinsonism with pleomorphic pathology. Neuron. 2004;44:601-7

34. Kumaran R, Cookson MR. Pathways to Parkinsonism Redux: Convergent path biological mechanisms in genetics of Parkinson's disease. Hum Mol Genet. 2015;24:R32-44.

35. Lin MK, Farrer MJ. Genetics and genomics of Parkinson's disease. Genome Med. 2014;6:48 